\title{
Contrasting relationship between macro- and microviscosity of the gelatin- and starch-based suspensions and gels
}

\author{
Dmitry V. Gulnov ${ }^{1}$ Elena V. Nemtseva ${ }^{1,2}$. \\ Valentina A. Kratasyuk ${ }^{1,2}$
}

Received: 12 December 2015/Revised: 8 March 2016/Accepted: 5 April 2016

(C) Springer-Verlag Berlin Heidelberg 2016

\begin{abstract}
The problem of correlation between rheological properties in macroand micro- scales of media with biopolymers of polypeptide (gelatin) and polysaccharide (starch) nature is investigated. The viscosity of the biopolymer solutions with concentrations $0.5-5 \mathrm{wt} \%$ was estimated by standard rotational rheometry technique and with fluorescent molecular rotor at $15-50{ }^{\circ} \mathrm{C}$. Opposite trends were observed for relationship between microviscosity $\eta_{\mathrm{m}}$ and macroviscosity $\eta$ for two biopolymers: $\eta_{\mathrm{m}}<<\eta$ for gelatin and $\eta_{\mathrm{m}}>>\eta$ for starch solutions. The temperature dependence of $\eta_{\mathrm{m}}$ followed the monoexponential decay law in all samples over the whole temperature range indicating insensitivity of microviscosity to gel mesh melting under heating. The dissimilarity of macro- and micro-rheological properties of gelatin and starch-containing media is discussed in terms of difference in architecture of the gels.
\end{abstract}

Keywords Biopolymer - Gelatin - Starch · Physical gel · Microviscosity · Molecular rotor

\section{Introduction}

Currently biological polymers gelatin and starch are widely used in biotechnology in media for enzyme immobilization [1-5] or in responsive polymer systems for controlled drug delivery [6]. Gelatin and starch gels meet many requirements for media suitable for immobilization of the biological components (high mechanical strength, porosity, etc.). At the same time, being natural biopolymers, they are non-

Dmitry V. Gulnov

dgulnov@sfu-kras.ru

1 Laboratory of Bioluminescent Biotechnologies, Siberian Federal University,

Krasnoyarsk 660041, Russia

2 Institute of Biophysics SB RAS, Krasnoyarsk 660036, Russia 
toxic, biocompatible, biodegradable, and abundant (Fig. 1a, b) [1]. Important physico-chemical characteristic of gelatin and starch solutions and gels is the increased viscosity, which affects the rate of diffusion of both the immobilized (entrapped) components and analyte molecules. Viscosity change can influence the functional activity of proteins included into the gel, as well as the rate of drug release [2-6].

But in many cases viscosity quantifying is a problem for the media, containing polymeric compounds. It is caused by the fact that the resulting viscosity depends on the spatial scale of measuring technique used. Standard methods of rotational or capillary viscosimetry mainly characterize the relative motion of the whole macromolecular chains and media layers [7]. Viscosity defined in such a way is called macroviscosity $(\eta)$. At the same time the diffusion rate of small molecules (probes) in gel-like media often depends on the properties of the solvent included in the gel matrix and the segmental motion of macromolecules. Such viscosity defined from diffusion rate of probe molecule in the media with the biopolymer is often called microviscosity $\left(\eta_{\mathrm{m}}\right)$. The functional relationship between these two types of viscosity has not been established yet as it significantly varies depending on the type of biopolymer, sample preparation method and viscosity measurement technique. Typically, only one type of viscosity is estimated, without paying attention to another. Meanwhile, the comparison of the macro- and microviscosity values ( $\eta$ and $\eta_{\mathrm{m}}$ ) for the biopolymer solution can give important information about the impact of the gelation process on the mobility of components included into the suspension or gel.

In standard rotational viscosimetry technique the medium macroviscosity is determined as proportionality factor between the shear rate and shear stress (granting the linear dependence between characteristics, i.e. "Newtonian" behavior of the sample). Gel-like media as a rule feature "non-Newtonian" behavior and complex viscosity is measured by oscillation mode in this case [8].

Microviscosity measuring techniques are very diverse and values obtained often depend on the method applied [9]. Recently, the molecular rotors are widely used to probe viscosity changes in complex biological samples including cytoplasm [1016]. Molecular rotors are fluorescent molecules that deactivate the excited state through rotational movement (Fig. 1c). In that case, the microviscosity is defined from quantum yield of probe fluorescence $(\Phi)$ using the Forster-Hoffmann equation:

$$
\log \Phi=C+x \log \eta_{\mathrm{m}}
$$

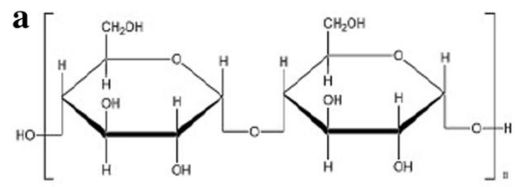

b
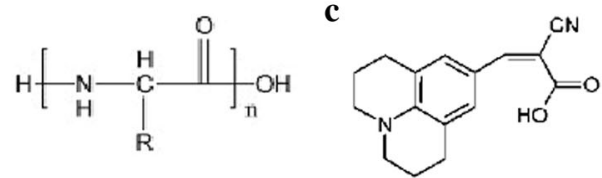

Fig. 1 Structure of the starch (a) and gelatin (b) monomers and the molecular rotor CCVJ (c). $R$ is the amino acid side chain 
where $C$ and $x$ are the temperature-dependent and probe-dependent constants, respectively. This equation was obtained analytically $[10,12]$ and verified experimentally [17]. Examples of molecular rotors application include the polymerization reaction control [10], the assessing the rheological characteristics of blood plasma and plasma expanders [15] and development of the biofluid viscosity sensor [16].

The aim of the current study was to analyze the relationship between macro- and microviscosity of solutions and gels based on potato starch and gelatin that were used for immobilization of enzymes from luminous bacteria [2-5]. The increasing enzyme activity and stability were revealed at certain concentrations of biopolymers [2-5]. In this context, information on media viscosity is an important element in understanding the mechanisms underlying observed effects. Samples with biopolymer content $0.5-5 \mathrm{wt} \%$ at temperature range $10-50{ }^{\circ} \mathrm{C}$ were tested. To evaluate $\eta_{\mathrm{m}}$ the fluorescent probe 9-(2-carboxy-2-cyanovinyl)-julolidine (CCVJ) was used (Fig. 1c). The size of this molecular rotor is comparable to that of the substrates of bioluminescent enzymes, so its diffusion rate can characterize the microenvironment viscosity of immobilized enzymatic reactions [4].

\section{Experimental}

\section{Materials}

The following reagents were used: glycerol (Gerbu), soluble potato starch (Lintner) of analytical grade (Serva), gelatin with a bloom number of 180 (Fluka), viscosity probe CCVJ (Sigma), salts for buffer solution $\mathrm{K}_{2} \mathrm{HPO}_{4}$ and $\mathrm{KH}_{2} \mathrm{PO}_{4}$ (Fluka).

\section{Sample preparation}

Biopolymer solutions in phosphate buffer $(0.05 \mathrm{M}, \mathrm{pH} 6.9)$ were used; the content of the starch or gelatin varied within $0.5-5 \mathrm{wt} \%$.

Gelatin and starch solutions were prepared in accordance with the procedure applied for enzyme immobilization: a mixture of buffer and gelatin was heated to $80{ }^{\circ} \mathrm{C}$ under continuous stirring to melt the gelatin completely, then cooled to room temperature without mixing; a mixture of buffer and starch powder was boiled for $3 \mathrm{~min}$, then cooled to room temperature without mixing [5]. Just prepared samples were poured into the temperature-controlled cell of fluorimeter or rheometer and thermostated for at least $10 \mathrm{~min}$ before measuring spectra or rheological characteristics.

The aliquot of the CCVJ stock solution in phosphate buffer was added into the studied samples to obtain final concentration $3 \mu \mathrm{M}$. Calibration of the fluorescent probe by finding the coefficients $C$ and $x$ (1) was carried out using the bufferglycerol mixtures with glycerol content of 20, 40, 60 and $80 \mathrm{wt} \%$ [18]. Fluorescence measurements were made just after thorough mixing of buffer with glycerol and CCVJ. 


\section{Spectroscopy}

Fluorescence emission spectra of CCVJ were measured with Fluorolog-3 spectrofluorometer (Horiba Jobin-Yvon, France). Excitation wavelength used was $420 \mathrm{~nm}$ and spectral bandwidth was $2.8 \mathrm{~nm}$. The system temperature was controlled by a refrigerated circulating bath WCR-P8 (Daihan Scientific, Korea). Fluorescence spectra were corrected for the emission sensitivity characteristics of the instrument and inner filter effect [19].

The absorption spectra were measured with a Cary 5000 spectrophotometer (Agilent Technologies, Australia) with integrated Pelletier temperature controller. Spectral slitwidth was $2 \mathrm{~nm}$.

\section{Rheology}

The rheological properties of the polymer solutions were measured using modular rheometer PHYSICA MCR501 (AntonPaar, Switzerland), with a measuring system CC27/T200/AL based on concentric cylinders (cell diameter $28.92 \mathrm{~mm}$, gap $1.13 \mathrm{~mm}$, sample volume $19.35 \mathrm{~mL}$ ) and Pelletier heating system. Tests were performed in dynamic mode, running first strain sweeps between 10 and $1000 \mathrm{~s}^{-1}$ to evaluate the linear viscoelastic response of the sample at $20{ }^{\circ} \mathrm{C}$. For all starch samples and $0.5,1$ and $2 \%$ gelatin samples the share rate $50 \mathrm{~s}^{-1}$ was chosen for viscosity measurement at $15-50{ }^{\circ} \mathrm{C}$. For the gelatin gels ( 3 and $5 \mathrm{wt} \%$ ) storage and loss moduli $G^{\prime}$ and $G^{\prime \prime}$ were measured in dynamic mode (frequency- $10 \mathrm{~Hz}$, amplitude $-0.5 \%$ ) as function of temperature in the range of $15-50{ }^{\circ} \mathrm{C}$. The gel melting point, also called critical temperature, was defined as the temperature where $G^{\prime}=G^{\prime \prime}[20]$.

\section{Temperature dependence}

Viscosity-temperature relation was evaluated using Doolittle equation:

$$
\eta=A \cdot e^{\frac{E_{\mathrm{a}}}{R T}}
$$

where $\eta$ is the viscosity of the polymer solution ( $\mathrm{Pa} \mathrm{s}), A$ is a pre-exponential factor (Pa s), $R$ is the gas constant $\left(8.314 \mathrm{~J} \mathrm{~K}^{-1} \mathrm{~mol}^{-1}\right)$, $\mathrm{T}$ is the thermodynamic temperature $(\mathrm{K})$ and $E_{\mathrm{a}}$ is the activation energy of viscous flow $\left(\mathrm{J} \mathrm{mol}^{-1}\right)$.

\section{Results and discussion}

\section{Macroviscosity of the media with biopolymers}

Prior to rheological measurements of concentration- and temperature-dependence of sample viscosity the conditions were defined at which the investigated media behave as Newtonian fluids. The share viscosity of all samples was measured at $20{ }^{\circ} \mathrm{C}$ as proportionality factor between shear stress and the shear rates within the 
range $1-1000 \mathrm{~s}^{-1}$. For all starch solutions and for gelatin samples with $0.5-2 \mathrm{wt} \%$ of the biopolymer it was found that the viscosity remains constant within shear rates 25-125 s $\mathrm{s}^{-1}$ (Fig. 2a). For further macroviscosity measurements the shear rate $50 \mathrm{~s}^{-1}$ was selected for these samples. Such "Newtonian" region was observed even for more concentrated potato starch samples (15\%), but at much lower share rates [21].

Contrasting results were obtained for 3 and $5 \mathrm{wt} \%$ gelatin solutions: starting from significantly higher values (compare ordinate scales in Fig. 2a, b) their apparent viscosity declines by a power law with increasing shear rate (Fig. 2b). Such a deviation from "Newtonian" behavior is known as pseudoplasticity and is typical for the polymers that tend to form the network with temporary junction [8]. Oscillating measuring mode is used in such cases, so for the samples containing 3 and $5 \mathrm{wt} \%$ gelatin complex viscosity values $\eta^{*}$ were obtained in dynamic oscillatory mode at a frequency of $10 \mathrm{~s}^{-1}$ and amplitude $0.5 \%$.

The resulting temperature dependences of samples macroviscosity are shown in Figs. 3 and 4. It is clear that for the most gelatin samples it follows the exponential low only at heating above $35^{\circ} \mathrm{C}$, whereas for starch solutions whole temperature range can be described by this function. In the range of $25-35^{\circ} \mathrm{C}$ the macroviscosity of the most concentrated gelatin samples dramatically decreases (Fig. 4) that can reflect the melting the gel mesh under heating. A loss tangent value (equal to $G^{\prime \prime} / G^{\prime}$ ) indicates that before $30{ }^{\circ} \mathrm{C}$ the deformation is essentially recoverable and the gelatin gel behaves more like a solid, whereas at higher temperatures large $G^{\prime \prime} / G^{\prime}$ reflects that sample becomes less stiff, behaving more like a liquid [22]. The temperature dependences (Fig. 4) allowed defining the gel

$\mathbf{a}$

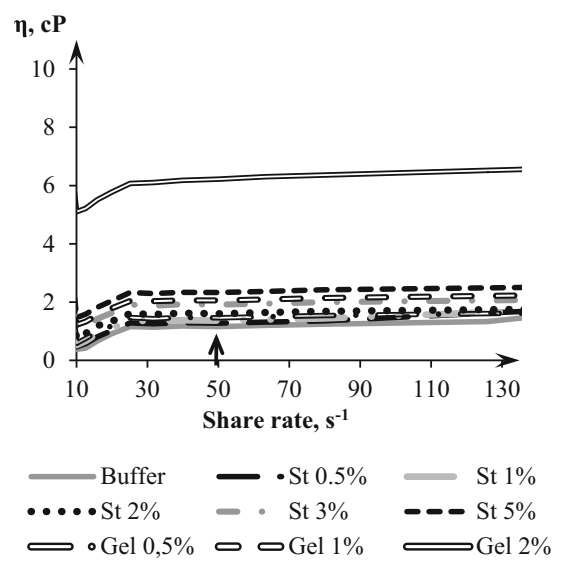

b

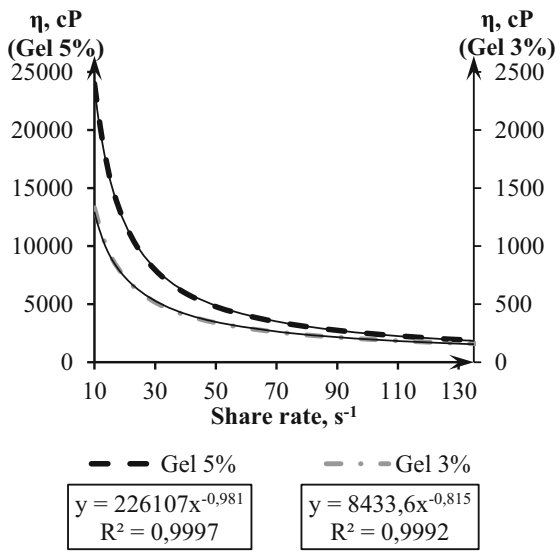

Fig. 2 Steady shear flow viscosity as a function of the shear rate for starch (St) and gelatin (Gel) samples $\left(20{ }^{\circ} \mathrm{C}\right)$ : a "Newonian" behavior for all starch suspensions and samples with $0.5-2 \mathrm{wt} \%$ of the gelatin (arrow indicates the chosen shear rate), b "pseudoplastic" behavior of the 3 and $5 \%$ gelatin solutions (the lines power law approximations, in the frames the corresponding equations with the coefficient of determination $R^{2}$ ) 


\section{a}

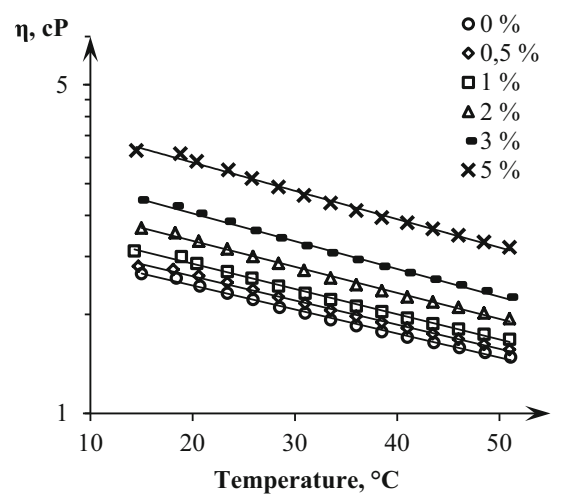

b

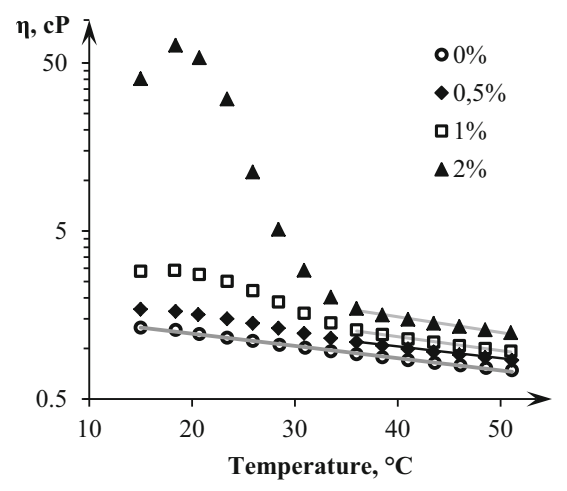

Fig. 3 Macroviscosity vs. temperature for starch (a) and gelatin (b) solutions at a shear rate $50 \mathrm{~s}^{-1}$ (semi-logarithmic scale, the lines exponential approximations)

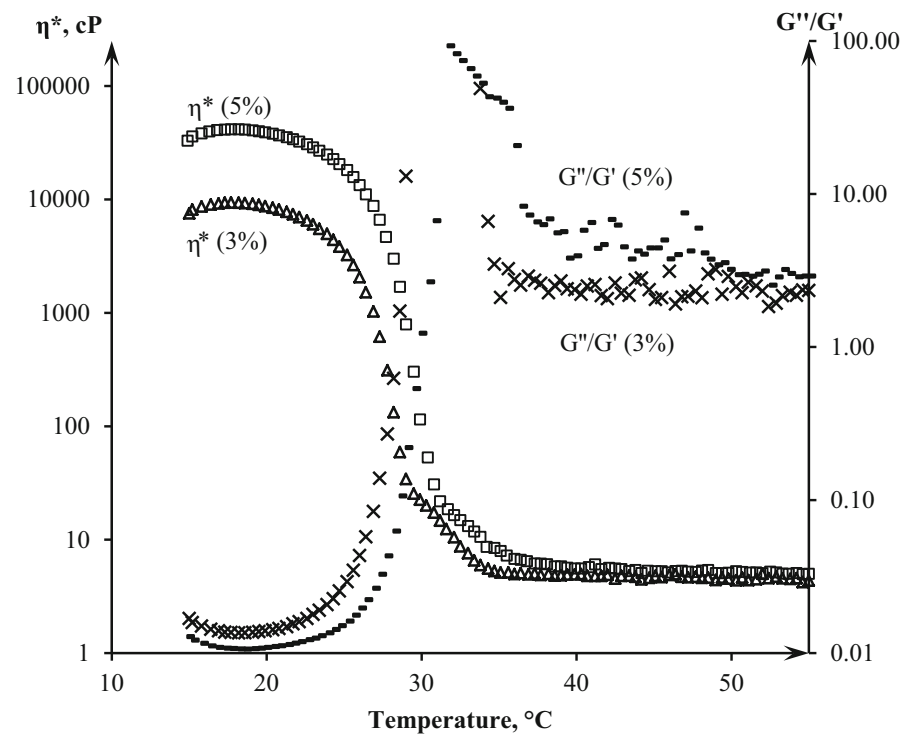

Fig. 4 Complex viscosity $\eta^{*}$ and $G^{\prime \prime} / G^{\prime}$ vs. temperature for samples with 3 and 5 wt $\%$ of gelatin (frequency $10 \mathrm{~s}^{-1}$ )

melting temperature of the samples with 3 and 5 wt $\%$ gelatin: 28.5 and $30{ }^{\circ} \mathrm{C}$, respectively, which is in good agreement with published data [20].

Using linear ranges (in a semi-logarithmic scale) the apparent activation energies of viscous flow were estimated according to Eq. (2), as summarized in Table 1. It can be seen that for starch samples activation energy increases gradually, but in a small amount. 
Table 1 Apparent activation energy of viscous flow $E_{\mathrm{a}}^{*}$ for macroviscosity of the studied samples

\begin{tabular}{llll}
\hline No & $\begin{array}{l}\text { Viscogen } \\
\text { concentration } \\
(\text { wt } \%)\end{array}$ & $\begin{array}{l}\text { Macroviscosity } \\
\eta\left(20{ }^{\circ} \mathrm{C}\right), \mathrm{cP}\end{array}$ & $E_{\mathrm{a}}^{*}\left(\mathrm{~kJ} \mathrm{~mol}^{-1}\right)$ \\
\hline $\begin{array}{c}\text { Buffer } \\
1\end{array}$ & 0 & 1.23 & 13.08 \\
Starch & & & \\
2 & 0.5 & 1.32 & 13.16 \\
3 & 1 & 1.44 & 13.73 \\
4 & 2 & 1.68 & 14.16 \\
5 & 3 & 2.05 & 15.12 \\
6 & 5 & 2.80 & 15.06 \\
Gelatin & & & $13.61^{\mathrm{a}}$ \\
7 & 0.5 & 1.60 & $15.99^{\mathrm{a}}$ \\
8 & 1 & 2.79 & $17.89^{\mathrm{a}}$ \\
9 & 2 & 55.4 & $6.06^{\mathrm{a}}$ \\
10 & 3 & $8720^{\mathrm{b}}$ & $10.21^{\mathrm{a}}$ \\
11 & 5 & $39100^{\mathrm{b}}$ & $14.7(18 \%)$ \\
Glycerol & & & $14.7(11 \%)$ \\
12 & 10 & $1.54(19 \%)$ & \\
13 & 20 & $1.94(11 \%)$ & \\
\hline
\end{tabular}

${ }^{\text {a }}$ Calculated according to the linear range $35-50{ }^{\circ} \mathrm{C}$

b Values of the complex viscosity $\eta^{*}$

${ }^{c}$ In parentheses the relative deviation from tabulated data [18] is shown

The fourfold difference in polymer concentration (from 0.5 to $2 \mathrm{wt} \%$ ) leads to an energy increment of $1 \mathrm{~kJ} \mathrm{~mol}^{-1}$ for starch, whereas for gelatin the increment is $4.86 \mathrm{~kJ} \mathrm{~mol}^{-1}$. The reported activation energy of pure water is about $15 \mathrm{~kJ} / \mathrm{mol}$ [23], which is close to the value obtained in current work for the buffer (Table 1). The temperature dependence of the viscosity of the buffer-glycerol mixtures measured by steady share stress technique under the same conditions as the samples with biopolymer is also characterized by $E_{\mathrm{a}}^{*}$ that well corresponds to the value, expected from data published earlier [18].

Generally, apparent activation energy of viscous flow is believed to rise with the increasing concentration of polymer [24]. It is caused by enhancing of the contacts and weak bond formation between polymer molecules at higher concentration. This interaction "resists" the viscous flow of the sample and increases the corresponding activation energy. Such trend can be seen for the samples based on starch, but it is broken for gelatin media. This can be accounted for the change of the viscosity measuring technique from the steady share tests (for first three concentrations) to the dynamic oscillation mode (for the last two). $E_{\mathrm{a}}^{*}$ can be correctly compared among samples with $0.5,1$ and $2 \%$ of gelatin and, separately, between 3 and $5 \%$ gels. Within these groups the tendency is kept: the apparent activation energy increases with a polymer concentration. 


\section{Microviscosity of the media with biopolymers defined by molecular rotor}

To estimate microviscosity, the spectral characteristics of the probe were measured in solutions with different concentrations of gelatin and potato starch and in reference buffer-glycerol solutions (Fig. 5; Table 2).

It can be seen that the absorption spectra of the probe vary slightly in viscous media. Fluorescence spectra changes are more pronounced: in viscous media blue shift is observed up to $9 \mathrm{~nm}$ in case of starch (Table 2). It indicates a lower polarity of probe microenvironment in the studied media if compared to buffer solution. This cannot be a hindrance to determine viscosity, because CCVJ can be used regardless of the media polarity. Its quantum yield depends only on the viscosity [25, 26]. It is worth noting that the obtained spectral shifts depended on biopolymer concentration, but not on the temperature of media.

To calculate the microviscosity values the calibration curve was obtained using buffer-glycerol mixtures at three temperatures (Fig. 6).

Figure 6 shows that within viscosity range $0.5-120 \mathrm{cP}$ the relationship between the fluorescence intensity and the medium viscosity is linear in double-logarithmic scale (Eq. 1), confirming that the probe molecule behaves in accordance with the

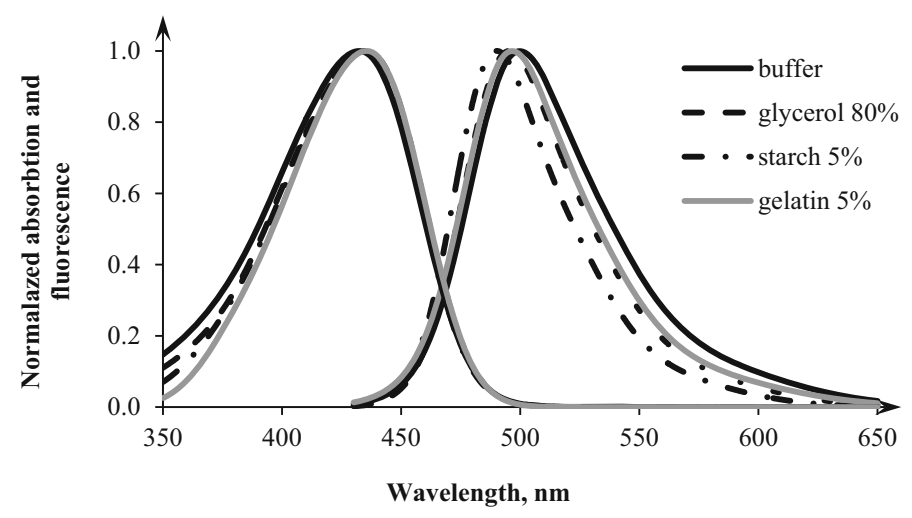

Fig. 5 Normalized absorption (left) and fluorescence (right) spectra of CCVJ in different media at $30{ }^{\circ} \mathrm{C}$

Table 2 Spectral characteristics of CCVJ in viscous media $\left(30{ }^{\circ} \mathrm{C}\right)$

\begin{tabular}{lllll}
\hline No & Medium & $\begin{array}{l}\text { Absorption, } \\
\lambda_{\max }(\mathrm{nm})\end{array}$ & $\begin{array}{l}\text { Fluorescence, } \\
\lambda_{\max }(\mathrm{nm})\end{array}$ & $\begin{array}{l}\text { Stokes shift } \\
(\mathrm{nm})\end{array}$ \\
\hline 1 & Buffer & 432 & 500 & 68 \\
2 & Glycerol, $80 \mathrm{wt} \%$ & 435 & 495 & 60 \\
3 & Gelatin, 5 wt\% & 435 & 497 & 62 \\
4 & Starch, 5 wt\% & 434 & 490 & 56 \\
5 & Sucrose, 20 wt\% & 436 & 500 & 64 \\
\hline
\end{tabular}




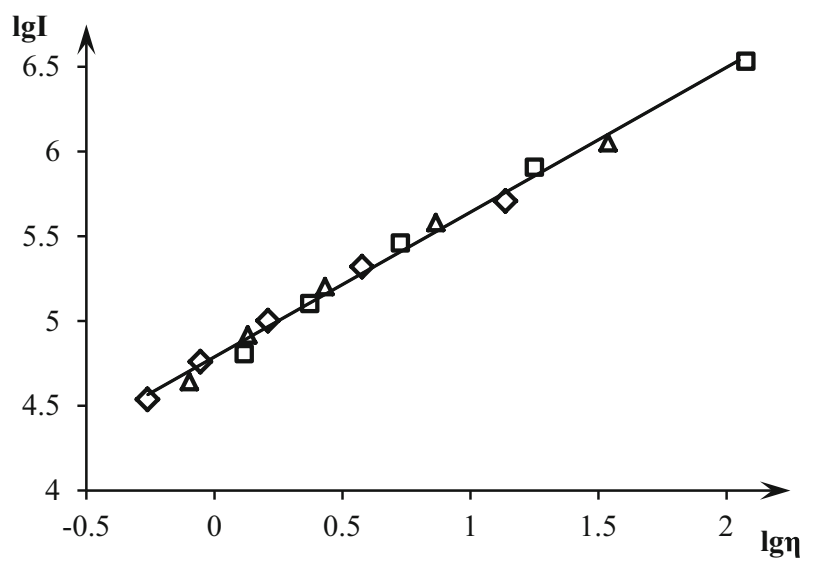

Fig. $6 \mathrm{CCVJ}$ fluorescence intensity (I) vs. viscosity of buffer-glycerol mixtures in double-logarithmic scale: $10^{\circ} \mathrm{C}$ (squares), $30{ }^{\circ} \mathrm{C}$ (triangles) and $50{ }^{\circ} \mathrm{C}$ (diamonds) (solid line calibration straight line)

Table 3 Apparent activation energy of viscous flow $E_{\mathrm{a}}^{*}$ for microviscosity of the studied samples

\begin{tabular}{llll}
\hline No & $\begin{array}{l}\text { Viscogen } \\
\text { concentration } \\
(\text { wt\% })\end{array}$ & $\begin{array}{l}\text { Microviscosity } \\
\left(20{ }^{\circ} \mathrm{C}\right), \mathrm{cP}\end{array}$ & $E_{\mathrm{a}}^{*}(\mathrm{~kJ} / \mathrm{mol})$ \\
\hline Starch & & & \\
1 & 0.5 & 6.53 & 45.7 \\
2 & 2 & 22.97 & 47.7 \\
3 & 5 & 68.28 & 44.7 \\
Gelatin & & & 21.9 \\
4 & 0.5 & 1.30 & 29.9 \\
5 & 1 & 1.86 & 34.9 \\
6 & 3 & 4.04 & 33.7 \\
7 & 5 & 5.40 & - \\
\hline Sucrose & & & \\
8 & $20 \%$ & $2.10(10 \%)$ & \\
\hline
\end{tabular}

${ }^{a}$ In parentheses the relative deviation from tabulated data [29] is shown

Forster-Hoffmann theory [15]. This relationship does not change within studied temperature range, what allows applying the same calibration equation for viscosity estimation at all temperatures. The method was tested by viscous solution with known macroviscosity: the fluorescence of CCVJ was measured in buffer with $20 \%$ of sucrose (Table 3). The obtained value of $\eta_{\mathrm{m}}$ was $2.1 \mathrm{cP}\left(20^{\circ} \mathrm{C}\right)$ that well corresponded to tabulated value of $\eta=2.0 \mathrm{cP}$ measured by a rolling ball technique [27].

Calculated microviscosities for gelatin and starch media upon heating are shown in the Fig. 7. It was revealed that $\eta_{\mathrm{m}}$ for starch solutions is approximately one order greater than that for gelatin solutions with identical biopolymer content (compare ordinate scales in Fig. 7a, b). 
a

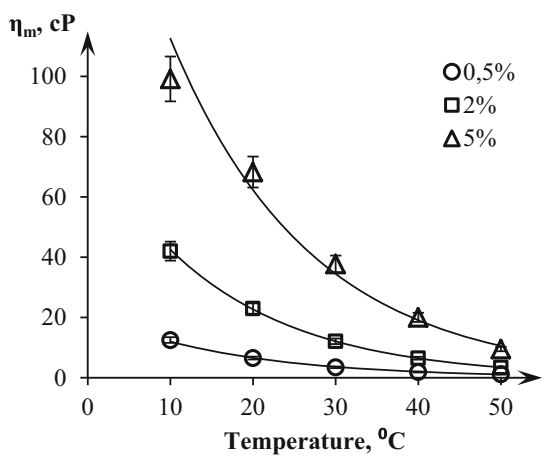

b

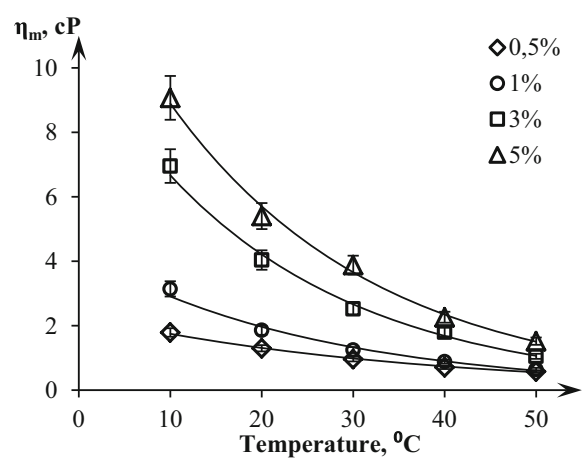

Fig. 7 Microviscosity vs. temperature for starch (a) and gelatin (b) solutions (solid lines are the exponential approximations)

It was found that upon heating the microviscosity decays exponentially for all concentrations of biopolymers (Fig. 7). Exponential temperature dependence is typical for liquids [28]. It implies that the calculated microviscosity characterizes mainly the behavior of the solvent (water) when increasing temperature. The apparent activation energy of viscous flow $E_{\mathrm{a}}^{*}$ was calculated for all samples according to Eq. (2) (Table 3).

It was obtained that for the starch solutions $E_{\mathrm{a}}^{*}$ changes slightly when increasing biopolymer content (Table 2). The activation energy obtained for minimal content of gelatin $(0.5 \mathrm{wt} \%)$ is about $21.9 \mathrm{~kJ} / \mathrm{mol}$. Further increase of the gelatin content leads to higher activation energy up to $34-35 \mathrm{~kJ} / \mathrm{mol}$.

The high microviscosity of the media with starch is caused by its structural properties. Potato starch is known to contain the linear amylose and branched amylopectin molecules, the last can impede the diffusion of smaller molecules, like CCVJ probe. Gel network in starch is formed by interactions between amylose chains, whereas more numerous amylopectin molecules mainly stay inside the granular residues in the random coil form. The fluorescent probe CCVJ, penetrated inside the amylopectin, manifests rather high viscosity of its microenvironment.

\section{Comparison of macro- and micro-viscosity}

The superposition of all the data obtained indicates that the interrelation between micro- and macroviscosity differs for polypeptide (gelatin) and polysaccharide (starch) solutions (Fig. 8). Media with 3 and 5 wt $\%$ gelatin are characterized by stronger macroviscosity (low fluidity). But their microviscosity only several times surpasses viscosity of water, i.e. diffusion of small molecules is slowed marginally. This finding is in good agreement with that of another investigation showing that small probe (like fluorescein) is unable to detect the gelatin transition from solution to gel [30]. 


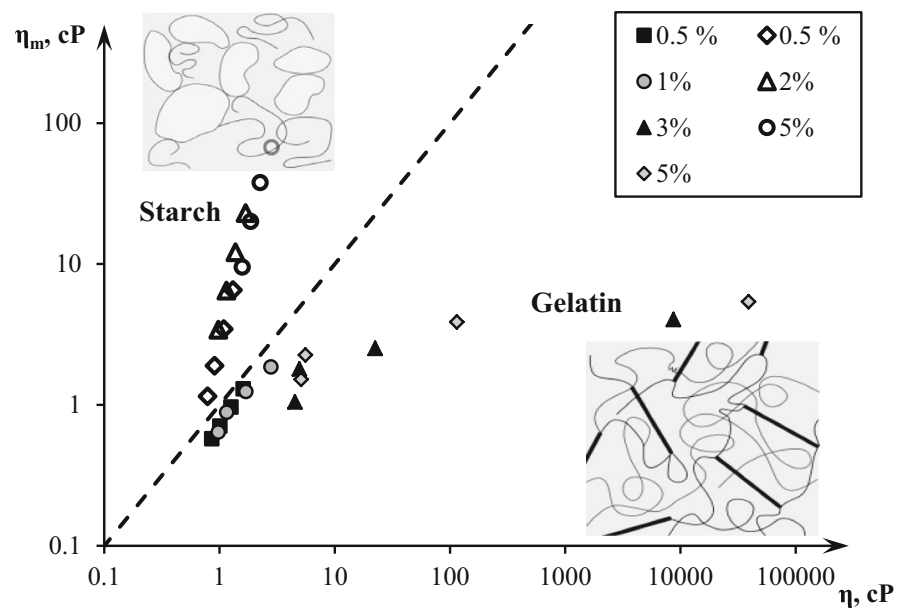

Fig. 8 Relationship between micro- $\left(\eta_{\mathrm{m}}\right)$ and macroviscosity $(\eta)$ for media with starch (empty markers) and gelatin (filled markers) at $20,30,40,50{ }^{\circ} \mathrm{C}$ (from right to the left). The dashed line represents the "ideal" fluid $\left(\eta_{\mathrm{m}}=\eta\right)$. Insets schematic structure of gelatin and starch gels

Media with starch reveal opposite feature: they are fluid enough and their macroviscosity exceeds that of water by not more than three times. But the diffusion of the components in such media can be very slow-measured microviscosity exceeds the viscosity of water in about 2 times of magnitude ( $5 \mathrm{wt} \%$ starch).

All results obtained in this investigation are summarized in Fig. 8. The linear dependence (in double logarithmic scale) between viscosities for different starch concentration allows finding the power function that relates $\eta_{\mathrm{m}}$ and $\eta$ for this media:

$$
\eta_{\mathrm{m}}=3.05 \cdot \eta^{3,15}\left(R^{2}=0.96\right) \text {. }
$$

It can be also seen (Fig. 8) that at low gelatin content (0.5 and $1 \mathrm{wt} \%) \eta_{\mathrm{m}}$ and $\eta$ values are very close to each other that is characteristic of unstructured medium (shown by the dashed line). At these concentrations the gelatin macromolecules do not interact with each other and the media have properties of true solution.

The observed contrast features of starch- and gelatin-containing media are mainly due to difference in their structural organization. Measured macrocharacteristics (Figs. 3, 4) indicate that among all samples the strong threedimensional network (gel) is formed only in solution with 3 and $5 \mathrm{wt} \%$ gelatin content. Indeed, the biopolymers under study feature the different critical concentration for gel formation. The gelatin solution is known to form gel on recooling after heating when the concentration is greater than 0.4-1.0\% [31], whereas the starch solution at the same conditions becomes a viscoelastic paste, which "sets up" into the gel at the starch concentration higher than $6 \mathrm{wt} \%$ [8]. It implies that in current investigation the gelatin gels could be formed, but the starch gels did not. It is worth noting that we did not aim at reaching the critical concentration for all the biopolymers under study, but tried to reveal the difference 
in rheological properties of the media, already applied for enzyme immobilization (up to $5 \mathrm{wt} \%$ of the biopolymer) [4]. Additionally it should be kept in mind that gelatin and starch form different types of gels_- "strong" and "weak", respectively, with essentially different rheological properties. Both strong and weak gels respond as solids at small deformations, but whereas the former are also solids at larger deformation, the latter flow under such conditions [31]. The gelatin gels contain extended physical cross-links or "junction zones" formed by a partial reversion to ordered "triple helical collagen-like" sequences. The starch gel is a result of the networks formation by interactions between leached amylose molecules, whereas more numerous amylopectin molecules (that lost their crystallinity) mainly stay inside the granular residues in the random coil form. So, the "weakness" of the gel structures is also the reason of fluid-like behavior of starch suspensions under steady share test.

Also the data point out that fluorescent probe is insensitive to the polymeric mesh formation and its melting during heating (Fig. 7). It means that the mesh size is much larger than the diameter of the probe and no hindrance for its diffusion occurs in gelatin gels. Indeed, the mesh size in gel of $5 \mathrm{wt} \%$ gelatin was estimated to be $51 \pm 2 \AA$ [32] while the diameter of CCVJ molecule is about $7 \AA$. Different situation is observed in the media with potato starch, which consists of two structural components: linear amylose molecules (20-30\%) and branched amylopectin molecules (70-80 \%). There is a number of experimental data to suggest that the starch gel matrix with mesh size 35-36 nm [33] is formed by amylose chains while amylopectin functions as a solute in water that is compartmentalized by network [34]. In this case the used fluorescent probe gets into a "tangle" of amylopectin and faces significant diffusion difficulties, which is reflected in the high values of the calculated microviscosity of media with starch. This assumption is supported by the hypsochromic shift of the probe fluorescence spectrum observed in the media with starch (Fig. 5) that indicates the microenvironment with lower polarity [35]. It should be noted that the CCVJ fluorescence in solution with sucrose $(20 \mathrm{wt} \%)$ has no hypsochromic shift (Table 1) that means the absence of specific interactions between the probe and the monosaccharide groups. Earlier this probe was used to measure the viscosity of starch solutions, and the high microviscosity at very low concentrations of hydroxyethyl starch was also observed [36].

The obtained characteristics of biopolymer solutions allow approaching the mechanisms underlying the media effects on the activity of coupled-enzyme system NAD(P)H:FMN-oxidoreductase + bacterial luciferase observed earlier. It was shown that media with 1 and $5 \mathrm{wt} \%$ gelatin enhance the activity of this coupledenzyme system about twofold under the temperatures $\leq 20$ and $\leq 25{ }^{\circ} \mathrm{C}$, respectively [4]. After further heating the inhibition effect was observed. For the media with $2 \mathrm{wt} \%$ of potato starch the different trend was obtained: the inhibition of the coupled-enzyme system under the temperatures $\leq 20{ }^{\circ} \mathrm{C}$ and no effect after further heating as compared with buffer solution.

The results of current research generally support the idea of a critical role of the polymeric mesh formation for activation of enzymatic reactions in the case of gelatin. Indeed, the macroviscosity of the samples with 1 and $5 \mathrm{wt} \%$ gelatin dramatically decreases after 20 and $25{ }^{\circ} \mathrm{C}$, respectively (Figs. 3, 4) that means 
melting of the gel mesh. Low microviscosity of these samples (Fig. 7) indicates insignificant diffusion restriction for substrates of reaction and points out on the interaction of gelatin polymeric mesh with enzymes. Conversely, the inhibition of enzymatic reactions in a medium with $2 \mathrm{wt} \%$ starch may be due to difficulties of diffusion (high microviscosity, Fig. 7), which is removed with increased temperature.

Additionally, the variety of properties can be an advantage when it comes to practical application of biopolymers. Gelatin-based gels are rugged, recalling the solids by its physical state, forming some kind of skeleton, such that small molecules can easily diffuse through. Opposite to this, a suspension of starch (in particular, the potato starch which is characterized by a high content of amylopectin) is not able to form strong gels [37], but according to our results, it can provide a high degree of immobilization probably due to hydrophobic interactions. All features of the studied biopolymer types have many applications as they both are widely used individually, and in combination with each other [38]. Also, recently the media with gelatin and starch were shown to be proper surroundings to simulate the intracellular environment for enzymatic reactions [2, 39]. Here it can be mentioned that the environment with polypeptide and polysaccharides simulate different intracellular space areas with various structural organization. It can be assumed that the gelatin gels simulate the cytoskeleton and the general poroelastic behavior of the cytoplasm [40-42]. Starch suspensions imitate the media with inhomogeneous polarity and viscosity, which is typical characteristic for the cell [43].

\section{Conclusions}

Different trends of $\eta_{\mathrm{m}}(\eta)$ dependence for gelatin and potato starch solutions were obtained in this work, highlighting the complexity of determining the physical and chemical characteristics of the solutions with polymers at the micro-scale, basing only on the macro-properties of the samples (which are usually easier to measure). It is considered that few of the functional properties of biopolymers are directly governed by their primary sequence structure, and the main factor is the spatial conformation which biopolymer takes in solution. But in our case, it is obvious that for an accurate interpretation of the micro-characteristics values obtained the detailed understanding of the "architecture" of the internal space environments with biopolymers is required, which is related to the chemical nature of the macromolecules.

Acknowledgments Authors thank Alexander Kheruvimov (REC "Composite Materials and Structures", SUSU, Chelyabinsk, Russia) for assistance in rheological experiments. The research was partially supported by the grants No. 11.G34.31.0058 and 1762 from The Ministry of Education and Science of the Russian Federation and by the state budget allocated to the fundamental research at the Russian Academy of Sciences (Project No. 01201351504). 


\section{References}

1. Brena BM, Batista-Viera F (2006) Immobilization of enzymes. a literature survey. In: Guissan JM (ed) Immobilization of enzymes and cells, 2nd edn. Humana press, Tottowa, pp 15-30

2. Kratasyuk VA, Esimbekova EN (2003) Polymer immobilized bioluminescent systems for biosensors and bioinvestigations. In: Arshady R (ed) Introduction to polymeric biomaterials, the PBM series, vol 1. Citus Books, London, pp 301-343

3. Esimbekova E, Kratasyuk V, Shimomura O (2014) Application of enzyme bioluminescence in ecology. Adv Biochem Eng Biotechnol 144:67-109

4. Bezrukikh A, Esimbekova E, Nemtseva E, Kratasyuk V, Shimomura O (2014) Gelatin and starch as stabilizers for the coupled enzyme system of luminous bacteria NADH: FMN-oxidoreductaseluciferase. Anal Bioanal Chem 406:5743-5747

5. Esimbekova EN, Kratasyuk VA, Torgashina IG (2007) Disk-shaped immobilized multicomponent reagent for bioluminescent analyses: correlation between activity and composition. Enzyme Microb Technol 40:343-346

6. Bajpai AK, Shukla SK, Bhanu S, Kankane S (2008) Responsive polymers in controlled drug delivery. Prog Polym Sci 33:1088-1118

7. Khair AS, Brady JF (2008) "Microviscoelasticity" of colloidal dispersions. J Rheol 49:1449-1481

8. Picout DR, Ross-Murphy SB (2003) Rheology of biopolymer solutions and gels. Sci World J 3:105-121

9. Puchkov EO (2014) Intracellular viscosity: methods of measurements and role in metabolism. Biol Membrany 31:3-13. doi:10.1134/S1990747813050140

10. Loutfy RO (1986) Fluorescence probes for polymer free-volume. Pure Appl Chem 58:1239-1248

11. Iwaki T, Torigoe C, Noji M, Nakanishi M (1993) Antibodies for fluorescent molecular rotors. Biochemistry 32:7589-7592

12. Kung CE, Reed JK (1989) Fluorescent molecular rotors: a new class of probes for tubulin structure and assembly. Biochemistry 28:6678-6686

13. Sawada S, Iio T, Hayashi Y, Takahashi S (1992) Fluorescent rotors and their applications to the study of GF transformation of actin. Anal Biochem 204:110-117

14. Iio T, Takahashi S, Sawada S (1993) Fluorescent molecular rotor binding to actin. J Biochem 113:196-199

15. Haidekker MA, Tsai AG, Brady T, Stevens HY, Frangos JA, Theodorakis E, Intaglietta M (2002) A novel approach to blood plasma viscosity measurement using fluorescent molecular rotors. Am J Physiol Heart Circ Physiol 282:H1609-H1614

16. Haidekker MA, Grant Sh, Theodorakis E, Intaglietta M, Frangos JA (2011) Supported molecular biofluid viscosity sensors for in vitro and in vivo use. US Patent 7,943,390, May 17, 2011

17. Kuimova MK, Botchway SW, Parker AW, Balaz M, Collins HA, Harry L, Anderson HA, Suhling K, Ogilby PR (2009) Imaging intracellular viscosity of a single cell during photoinduced cell death. Nat Chem 1:69-73

18. Cheng NS (2008) Formula for the viscosity of a glycerol-water mixture. Ind Eng Che Res 47:3285-3288

19. Lakowicz JR (2006) Instrumentation for fluorescence spectroscopy. In: Lakowicz JR (ed) Principles of fluorescence spectroscopy, 3rd edn. Springer, New York, pp 27-62

20. Michon C, Cuvelier G, Launay B (1993) Concentration dependence of the critical viscoelastic properties of gelatin at the gel point. Rheol Acta 32:94-103

21. Carrillo-Navas H, Hernández-Jaimes C, Utrilla-Coello RG, Meraz M, Vernon-Carter EJ, AlvarezRamirez J (2014) Viscoelastic relaxation spectra of some native starch gels. Food Hydrocolloid 37:25-33

22. Ai Y, Jane J (2015) Gelatinization and rheological properties of starch. Starch Stärke 67:213-224

23. Haj-Kacem RB, Ouerfelli N, Herráez JV (2015) Viscosity Arrhenius parameters correlation: extension from pure to binary fluid mixtures. Phys Chem Liquids 53:776-784

24. Okada R, Tanzawa H (1965) Apparent activation energy for the viscous flow of polymer solutions. J Polym Sci A 3:4294-4296

25. Loutfy RO, Law KY (1980) Electrochemistry and spectroscopy of intramolecular charge-transfer complexes. pN, $N$-dialkylaminobenzylidenemalononitriles. J Phys Chem 84:2803-2808 
26. Haidekker MA, Brady TP, Lichlyter D, Theodorakis EA (2005) Effects of solvent polarity and solvent viscosity on the fluorescent properties of molecular rotors and related probes. Bioorg Chem 33:415-425

27. Först P, Werner F, Delgado A (2002) On the pressure dependence of the viscosity of aqueous sugar solutions. Rheol Acta 41:369-374

28. Durand A (2007) Aqueous solutions of amphiphilic polysaccharides: concentration and temperature effect on viscosity. Eur Polym J 43:1744-1753

29. Lide DR (ed) (2005) CRC handbook of chemistry and physics, internet version 2005. CRC Press, Boca Raton. http://www.hbcpnetbase.com

30. Hogman J, Loren N, Hermansson A-M (2010) Effect of gelatin gelation kinetics on probe diffusion determined by FRAP and rheology. Biomacromolecules 11:3359-3366

31. Ross-Murphy SB (1995) Structure-property relationships in food biopolymer gels and solutions. J Rheol 39:1451-1463

32. Cosgrove T, White SJ, Zarbakhsh A, Heenan RK, Howe AM, Cosgrove T et al (1995) Small-angle scattering studies of sodium dodecyl sulfate interactions with gelatin. 1. Langmuir 11:744-749

33. Miao Z, Ding K, Wu T, Liu Z, Han B, An G, Miao Sh, Yang G (2008) Fabrication of 3D-networks of native starch and their application to produce porous inorganic oxide networks through a supercritical route. Microporous Mesoporous Mater 111:104-109

34. Ohtsuka A, Watanabe T, Suzuki T (1994) Gel structure and water diffusion phenomena in starch gels studied by pulsed field gradient stimulated echo NMR. Carbohydr Polym 25:95-100

35. Rumble C, Rich K, He G, Maroncelli M (2012) CCVJ is not a simple rotor probe. J Phys Chem A 116:10786-10792

36. Akers W, Haidekker MA (2004) A molecular rotor as viscosity sensor in aqueous colloid solutions. J Biomech Eng 126:340-345

37. Ring SG (1985) Some studies on starch gelation. Starch Stärke 37:80-83

38. Zema L, Loreti G, Melocchi A, Maroni A, Gazzaniga A (2012) Injection molding and its application to drug delivery. J Control Release 159:324-331

39. Ling GN (2001) The polarized multilayer theory of cell water. In: Ling GN (ed) Life at the cell and below-cell level, 1st edn. Pacific Press, New York, pp 74-108

40. Feneberg W, Westphal M, Sackmann E (2001) Dictyostelium cells' cytoplasm as an active viscoplastic body. Eur Biophys J 30:284-294

41. Chandran PL, Barocas VH (2004) Microstructural mechanics of collagen gels in confined compression: poroelasticity, viscoelasticity, and collapse. J Biomech Eng 126:152-166

42. Moeendarbary E, Valon L, Fritzsche M, Harris AR, Moulding DA, Thrasher AJ, Stride EL, Mahadevan L, Charras GT (2013) The cytoplasm of living cells behaves as a poroelastic material. Nat Mater 12:253

43. Luby-Phelps K (1999) Cytoarchitecture and physical properties of cytoplasm: volume, viscosity, diffusion, intracellular surface area. Int Rev Cytol 192:189-221 